\title{
Anthós
}

\section{An Analysis of the Impact of Global Warming on Hurricane Activity in the United States}

Jesse Senzer

Portland State University

Follow this and additional works at: https://pdxscholar.library.pdx.edu/anthos

Part of the Climate Commons

Let us know how access to this document benefits you.

\section{Recommended Citation}

Senzer, Jesse (2012) "An Analysis of the Impact of Global Warming on Hurricane Activity in the United States," Anthós: Vol. 4: Iss. 1, Article 7.

https://doi.org/10.15760/anthos.2012.104

This open access Article is distributed under the terms of the Creative Commons Attribution-NonCommercialShareAlike 4.0 International License (CC BY-NC-SA 4.0). All documents in PDXScholar should meet accessibility standards. If we can make this document more accessible to you, contact our team. 
An Analysis of the Impact of Global Warming on Hurricane Activity in the United States

Jesse Senzer

Portland State University 


\begin{abstract}
This paper discusses the influence of global warming on ocean temperatures, and explains how vertical wind shear affects hurricane formation. It explores the scientific arguments against linking global warming to increased hurricanes, that ocean warming increases vertical wind shear in the main development region for Atlantic hurricanes, and that current/recent American hurricane trends fall within the realm of natural, multidecadal oscillations. Arguments supporting the link between global warming and hurricanes are addressed with climate modeling that links sea surface temperature (SST) increase to anthropogenic causes. It discusses SST’s influencing hurricane activity globally, if not locally to the U.S., and points to the need for consensus and action.
\end{abstract}




\section{Introduction}

Concentrations of greenhouse gases in the Earth’s atmosphere have steadily risen for over 100 years. The American and western European industrial revolution marked the beginning of a continuous global warming trend caused primarily by carbon dioxide accumulation in our atmosphere and oceans. Deforestation and the burning of fossil fuels on a global scale have caused an overabundance of heat-trapping carbon dioxide, which is in turn causing the average temperature of the Earth to steadily rise. What influence does the warming of the climate have on the temperature of the oceans? In 1990, the Intergovernmental Panel on Climate Change (IPCC) released its first scientific assessment of climate change research and concluded that a warming of about $0.3+\mathrm{C}$ had occurred over the last century in the Northern Hemisphere oceans, and about 0.3 虫 0.5 C in the Southern Hemisphere. This conclusion was based on volunteer observation ship, buoy, and weather ship data collected since the late 1800’s (Casey and Cornillon 2001). The warming climate is causing the average temperatures of the oceans to rise. Salinity changes, $\mathrm{pH}$, water vapor content, and ocean circulation patterns are all affected by global warming, in addition to the average temperatures of the surface layers of the sea.

Hurricane formation and strength is fueled by warm, humid waters. Warm, tropical regions typically see the highest rates of hurricane activity. Sea surface temperatures greatly influence wind speeds, with maximum wind speeds increasing by 5 knots in response to a mere $0.6 \notin \mathrm{C}$ increase in SST (Ahrens 2012). It seems a direct correlation can be made that increases in SST due to global warming are causing 
stronger, more frequent hurricane activity. In fact, the overall number of named Atlantic storms jumped up twice since 1900: in the late 1920’s and again in the mid-1990’s. That rise was roughly in step with lasting increases in the temperature of waters in the eastern tropical Atlantic, where most storms form (Kerr 2006). But this direct correlation assumption is problematic for two reasons: one, the most accurate data on the frequency and strength of tropical cyclones is only available post-1970's (due to satellite technology), and two, there is still some debate among the scientific community as to the accuracy of branding 'global warming' the culprit for stronger hurricane activity.

This analysis will discuss some of the arguments against connecting greenhouse gas emissions to stronger hurricanes, and the arguments supporting this connection, with recommendations for further research.

\section{Arguments Against Connecting Hurricane Activity to Global Warming and SST}

The relationship between vertical wind shear and landfalling Atlantic hurricanes is Effects of Vertical Wind Shear $\left(V_{z}\right)$ on Tropical Cyclones

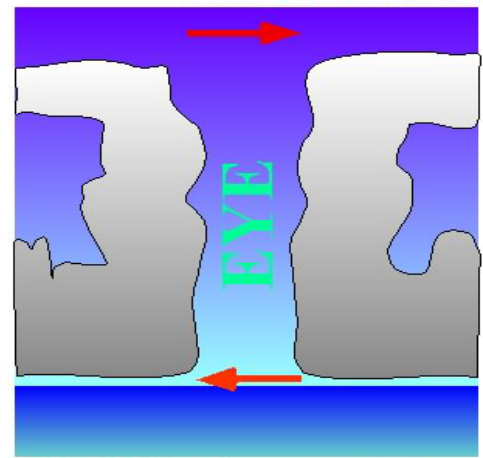

WEAK SHEAR = FAVORABLE

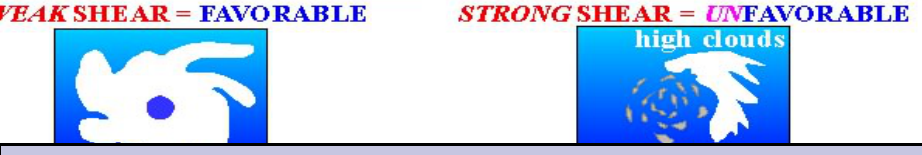

tropopause

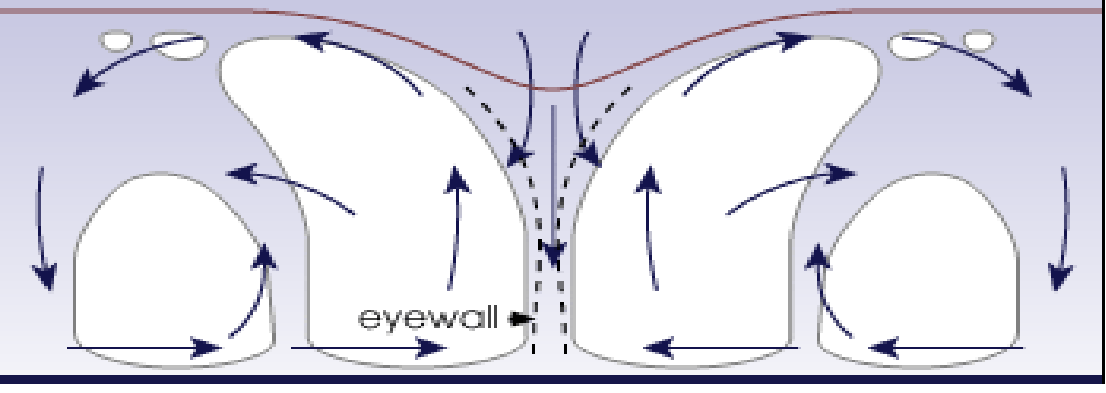

discussed by Chunzai

Wang and Sang-Ki Lee-

specifically that global

warming of the sea

surface is associated with

"a secular increase of

tropospheric vertical

wind shear" in the 
main development region (between western Africa and Central America) for Atlantic hurricanes. Vertical wind shear refers to the change in wind speeds and direction along the straight line from the Earth's surface to the top of the troposphere (Ahrens 2012). Therefore, an enhancement in tropospheric vertical wind shear is associated with a quiet hurricane season in the Atlantic basin, as it inhibits the organization of deep convection, and vice versa for a reduction in vertical wind shear (Wang and Lee 2008). As shown in the first illustration, high/strong wind shear inhibits hurricane formation by disturbing the developing atmospheric convection. As the hurricane forms, it can be literally blown apart by the different wind speeds of high vertical shear. Low wind shear allows convection to develop, increasing the winds circulating into and out of the eye of the storm (as shown in the second illustration).

Vertical wind shear is influenced by a number of factors in the main development region (MDR) for Atlantic hurricanes. In particular, warm water in the tropical eastern Pacific increases the wind shear in the tropical North Atlantic, primarily through its influence on the upper-level westerly flow. Therefore, the tropical oceans compete with one another for their impact on the vertical wind shear over the MDR for Atlantic hurricanes. Since the effects of warming in the tropical Pacific and Indian Oceans overcome that of the local warming in the tropical North Atlantic, the net result is an increase of the vertical wind shear in the MDR (Wang and Lee 2008). This influences Wang and Lee’s position that attributing the recent increase in Atlantic hurricane activity to global warming is “premature and that global warming may decrease the likelihood of hurricanes making landfall in the United States.” 
While there is always some degree of uncertainty about the future, and modelbased results are often fickle, the state of current understanding is such that we should expect hurricane frequencies in the future to have a great deal of year-to-year and decadeto-decade variation as has been observed in the past (Pielke, et al 2005). Pielke and coauthors reference studies that have addressed tropical cyclone intensity variations that show no significant trends during the decades of "reliable" records. They discuss the Atlantic multidecadel oscillation (AMO), and attribute that variability to natural causes rather than increases in greenhouse gases. They go on to add that in the absence of large or unprecedented trends, any effect of greenhouse gases on the frequency of storms or major hurricanes is necessarily very difficult to detect in the context of this documented variability (Pielke, et al 2005). Since the level of trends with regard to hurricanes needs to be "unprecedented" in order for some researchers to willingly make the greenhouse gas connection, it may be some time before there is enough data for consensus.

The issue of SST affects on hurricane wind strength is also the basis for some direct disagreement among scientists. A 2004 study from the Geophysical Fluid Dynamics Laboratory in Princeton, New Jersey, indicated the possibility of a 5\% increase in the wind speeds of hurricanes by $2080 \ldots$ These would imply that changes to hurricane wind speeds on the order of $0.5-1.0$ meters/sec may be occurring today. This value is exceedingly small in the context of, for example, the more than doubling in numbers of major hurricanes between quiet and active decadal periods in the Atlantic (Pielke, et al 2005). Other researchers have found that relatively modest changes in inner-core SST can dramatically alter air-sea fluxes within the high-wind inner-core storm environment. 
Initial estimates show that SST changes on the order of $1+\mathrm{C}$ lead to surface enthalpy flux changes of $40 \%$ or more (Cione and Ulhorn 2003). These are dramatic differences in opinion regarding the urgency of the current and future state of the atmosphere.

\section{Arguments for Connecting Hurricane Activity to Global Warming and SST}

Supporters of the idea that global warming is affecting hurricane activity point to the patterns and trends found in hotter climates. These can be seen as reinforcement that despite the debate over statistical intensity increases, something needs to be done about our changing climate. With a rising sea level due to warmer oceans melting the ice sheets, beach and wetland erosion and storm surges associated with tropical cyclones will cause greater impacts even if other aspects of tropical cyclones were to remain the same (Anthes, et al 2006). This addresses a key difference in the angle at which researchers approach the issue of global warming and hurricanes. On the side skeptical of making the link, researchers point to the data sets that show ambiguous connections at best. On the side supportive of making the link, broader trends are addressed using data to back up logical conclusions. For example, it is well known that tropical cyclones form only over warm oceans from which they gain their energy, largely from the latent heat of condensation. Thus, it would not be surprising if a warmer and moister world contained enhanced overall hurricane activity (Anthes, et al 2006).

This might give the impression that these arguments are rooted in logic rather than hard science, but that is not the case. B.D. Santer, et al examined 22 different climate models that suggest that century-time-scale SST changes of a magnitude ranging 
from $0.32+\mathrm{C}$ to $0.67+\mathrm{C}$ cannot be explained solely by unforced (natural) variability of the climate system. They specifically point to single-forcing experiments performed with the Parallel Climate Model of the National Center for Atmospheric Research. In this

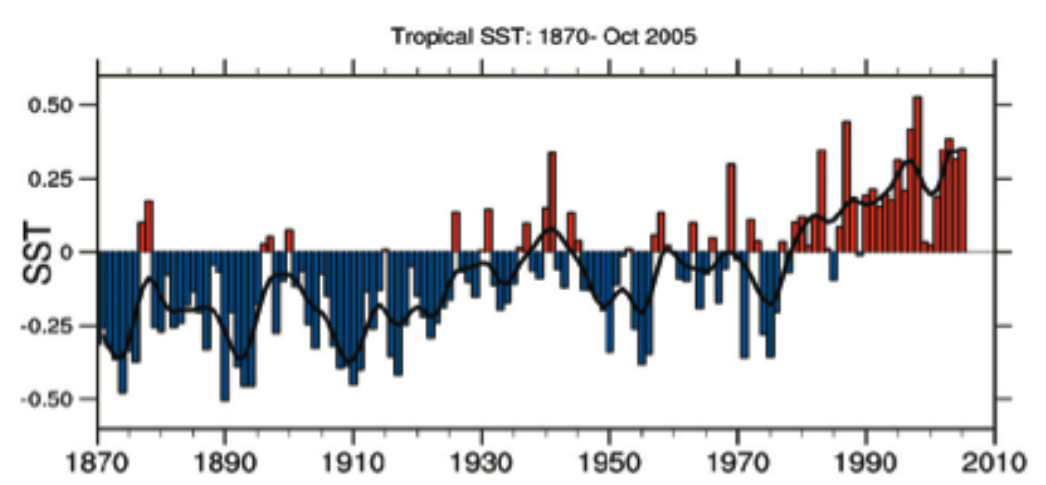
research the indication was that increases in well mixed greenhouse gases are the main driver of centurytimescale increases in Atlantic and Pacific tropical cyclogenesis region SST's (Santer, et al 2006).

In particular, the impact on tropical cyclones of multidecadal variations tends to be specific to each ocean basin and compensated globally by opposite fluctuations elsewhere. An increase of category 4 and 5 hurricanes in all ocean basins, and an overall global increase thereof has been observed. This is the type of weather that would be expected from global warming changes rather than from natural variability alone (Anthes, et al 2006). While the increased vertical wind shear in the Atlantic main development region may decrease landfalling hurricanes to the U.S., increased hurricane activity may occur elsewhere as part of this opposite fluctuation.

If the link between increased greenhouse gases and SST cannot be directly made to increased hurricane activity in the U.S. it may not be unreasonable to make the link to increasing hurricane activity worldwide. Seasonal measures of tropical cyclone intensity are positively correlated with tropical cyclone frequency in the north Atlantic. 
Consistently, one also sees an increase in average intensity during La Niña as compared to El Niño years, and one finds a trend toward higher intensities over the past three decades accompanying a trend toward an increased number of tropical cyclones (Zhao and Held 2010). The broad agreement between theoretical and modeling studies combined with the strong evidence from observational analysis suggests that not only will tropical cyclone intensity increase with anthropogenic warming, but that this process has already commenced (Anthes, et al 2006). There is no argument among the scientific community as to the influence of natural AMO variability, but some researchers imply that it is naïve and irresponsible to dismiss the increasing hurricane activity of recent decades as an exclusive result of this phenomena.

A primary conclusion that some scientists have reached with regard to the debate over the extent to which SST's and greenhouse gases are affecting hurricane activity, is that the "extent" at this point is irrelevant. For the period between 1906-2005, Santer and coauthors found an $84 \%$ chance that external forcing explains at least $67 \%$ of observed SST increases in the Atlantic and Pacific tropical cyclogenesis regions. In experiments in which forcing factors are varied individually rather than jointly, human-caused changes in greenhouse gases are the main driver of the $20^{\text {th }}$-century SST increases in both tropical cyclogenesis regions (Santer, et al 2006). To these researchers, the importance lies in the fact that anthropogenic causes are changing the atmospheric and oceanic balance of the planet. To banter over the current severity of those changes is like playing roulette with the weather. 


\section{Concluding Remarks}

The phenomena of fluctuating hurricane activity is one influenced by a multitude of factors including wind shear, water vapor, ocean circulation, sea surface temperatures, latent heat, etc. It is a complex subject that provides neither side of the debate with linear conclusions. In fact, a common theme among most of the journal articles referenced was a recognition of the need for continued research in this field. Although changes in ocean surface temperatures may be a key influence on hurricane intensity, SST’s are only one of a variety of factors that control hurricane formation, evolution, and intensity. Detailed analyses of changes in other large-scale conditions that affect tropical cyclogenesis (such as wind shear and vertical stability) are required to obtain a more complete understanding of how hurricane activity has changed and may continue to change in a warming world (Santer, et al 2006).

A likely explanation as to why changes in upper-ocean thermal structure have never been directly and quantitatively linked to changes in storm intensity is due to a limited number of observations. Both from an oceanic and atmospheric standpoint, the inner core is the most difficult region to routinely and accurately observe within the hurricane environment (Cione and Ulhorn 2003). Without further research and continued work on technological innovations to increase access to the inner-workings of hurricanes, the scientific community will continue to struggle with conflicting data sets and studies. Historically, it is very difficult to get the international community to reach political consensus if the scientific community is not already there. If there is little doubt that anthropogenic global warming is causing our oceans to rise and increase in temperature, 
then there should be little doubt that these enormous changes are influencing the intensity and frequency of hurricanes to some degree. The "degree” to which hurricanes are influenced can continue to be debated by researchers, as long as the "fact" that they are influenced is not. 


\section{References}

Ahrens, C.D. 2012, Essentials of Meteorology, $6^{\text {th }}$ Ed. Brooks/Cole, Cengage Learning. Belmont, CA., pgs. 312-340.

Anthes, R.A. and Coauthors, 2006: Hurricanes and global warming- potential linkages and consequences. Bulletin of the American Meteorological Society, 87, 623-628.

Casey, K.S. and Cornillon, P., 2001: Global and regional sea surface temperature trends. Journal of Climate, 14, 3801-3818.

Cione, J.J. and Unlhorn, E.W., 2003: Sea surface temperature variability in hurricanes: Implications with respect to intensity change. Monthly Weather Review, 131, 1783-1796.

Kerr, R.A., 2006: Global warming may be homing in on Atlantic hurricanes. Science, 314, 910-911.

Pielke, R.A. and Coauthors, 2005: Hurricanes and global warming. Bulletin of the American Meteorological Society, 86, 1571-1575.

Rumpf, J. and Coauthors, 2010: Structural variation in genesis and landfall locations of North Atlantic tropical cyclones related to SST. Tellus: Series A, 62, 243-255.

Santer, B.D. and Coauthors, 2006: Forced and unforced ocean temperature changes in Atlantic and Pacific tropical cyclogenesis regions. Proceedings of the Nat'l. Academy of Sciences of the US, 103, 13905-13910.

Wang, C. and S.-K. Lee (2008): Global warming and United States landfalling hurricanes, Geophys. Res. Lett., 35, L02708, doi: 10.1029/2007GL032396.

Zhao, M. and Held, I.M., 2010: An analysis of the effect of global warming on the 
intensity of Atlantic hurricanes using a GCM with statistical refinement. Journal of Climate, 23, 6283-6293.

\section{Graphic References}

Anthes, R.A. and Coauthors, “Time series of global annual SST anomalies (

Bulletin of the American Meteorological Society, 87, May 2006, 624.

Goldman, J. “Vertical Shear.” www.noaanews.noaa.gov July 19, 2001. October 16, 2011. <http://www.noaanews.noaa.gov/stories/s682.htm>

Simmon, R. "Hurricane Profile Graphic.” www.earthobservatory.nasa.gov Aug 22, 2005. October 16, 2011.

$<$ http://earthobservatory.nasa.gov/Library/Hurricanes/Images/hurricane_section.gif 